\title{
Efficacy of Mesenchymal Stem Cells in Suppression of Hepatocarcinorigenesis in Rats: Possible Role of Wnt Signaling
}

\author{
Mohamed T Abdel aziz', Mohamed F El Asmar², Hazem M Atta', Soheir Mahfouz ${ }^{3}$, Hanan H Fouad', \\ Nagwa K Roshdy ${ }^{1}$, Laila A Rashed ${ }^{1}$, Dina Sabry ${ }^{1}$, Amira A Hassouna ${ }^{1 *}$ and Fatma M Taha ${ }^{1}$
}

\begin{abstract}
Background: The present study was conducted to evaluate the tumor suppressive effects of bone marrow derived mesenchymal stem cells (MSCs) in an experimental hepatocellular carcinoma (HCC) model in rats and to investigate the possible role of Wnt signaling in hepato-carcinogenesis.

Methods: Ninety rats were included in the study and were divided equally into: Control group, rats which received MSCs only, rats which received MSCs vehicle only, HCC group induced by diethylnitroseamine (DENA) and $\mathrm{CCl}_{4}$, rats which received MSCs after HCC induction, rats which received MSCs before HCC induction. Histopathological examination and gene expression of Wnt signaling target genes by real time, reverse transcription-polymerase chain reaction (RT-PCR) in rat liver tissue, in addition to serum levels of ALT, AST and alpha fetoprotein were performed in all groups.

Results: Histopathological examination of liver tissue from animals which received DENA-CCl ${ }_{4}$ only, revealed the presence of anaplastic carcinoma cells and macro-regenerative nodules type II with foci of large and small cell dysplasia. Administration of MSCs into rats after induction of experimental HCC improved the histopathological picture which showed minimal liver cell damage, reversible changes, areas of cell drop out filled with stem cells. Gene expression in rat liver tissue demonstrated that MSCs downregulated $\beta$-catenin, proliferating cell nuclear antigen (PCNA), cyclin D and survivin genes expression in liver tissues after HCC induction. Amelioration of the liver status after administration of MSCs has been inferred by the significant decrease of ALT, AST and Alpha fetoprotein serum levels. Administration of MSCs before HCC induction did not show any tumor suppressive or protective effect.
\end{abstract}

Conclusions: Administration of MSCs in chemically induced HCC has tumor suppressive effects as evidenced by down regulation of Wnt signaling target genes concerned with antiapoptosis, mitogenesis, cell proliferation and cell cycle regulation, with subsequent amelioration of liver histopathological picture and liver function.

\section{Background}

Hepatocellular carcinoma (HCC) is a highly prevalent, treatment-resistant malignancy with a multifaceted molecular pathogenesis[1]. It is a significant worldwide health problem with as many as 500,000 new cases diagnosed each year[2]. In Egypt, HCC is third among cancers in men with $>8000$ new cases predicted by 2012[3].

\footnotetext{
*Correspondence: amira_hassouna@yahoo.co.uk

'Unit of Biochemistry and Molecular Biology (UBMB), Department of Medical Biochemistry, Faculty of Medicine, Cairo University, Cairo, Egypt

Full list of author information is available at the end of the article
}

Current evidence indicates that during hepatocarcinogenesis, two main pathogenic mechanisms prevail: cirrhosis associated with hepatic regeneration after tissue damage and mutations occurring in oncogenes or tumor suppressor genes. Both mechanisms have been linked with alterations in several important cellular signaling pathways. These pathways are of interest from a therapeutic perspective, because targeting them may help to reverse, delay or prevent tumorigenesis[1]. In experimental animals interferon- $\alpha(I F N-\alpha)$ gene therapy exerts significant protective effects, but more so when the gene

\section{() Biomed Central}


is administered before fibrogenic and carcinogenic induction in hepatic tissues[4]. In humans, in the absence of any antiviral response, a course of interferon alpha does not reduce the risks of liver cancer or liver failure[5]. Whereas, after curative treatment of primary tumour; IFN-alpha therapy may be effective for the prevention of HCC recurrence[6]. Therefore providing new therapeutic modalities may provide a better way for treatment of HCC and amelioration of tumor mass prior to surgical intervention.

Advances in stem cell biology have made the prospect of cell therapy and tissue regeneration a clinical reality[7]. In this rapidly expanding field of cell based therapy, more attention has been paid to the relationship between stem cells and tumor cells. Qiao and coworkers reported that human mesenchymal stem cells (hMSCs) can home to tumor sites and inhibit the growth of tumor cells[8]. Furthermore, the authors reported that hMSCs inhibit the malignant phenotypes of the H7402 and HepG2 human liver cancer cell lines [9]. The stem cell microenvironment has an essential role in preventing carcinogenesis by providing signals to inhibit proliferation and to promote differentiation [10]. Furthermore, tumor cells may secrete proteins that can activate signaling pathways which facilitate hMSC migration to the tumor site [11]. Moreover, MSCs not only support hematopoiesis, but also exhibit a profound immune-suppressive activity that targets mainly T-cell proliferation[12]. In an animal model of hepatic injury, the researchers suggested that MSCs might become a more suitable source for Stem Cellbased therapies than hepatic stem cells, because of their immunological properties as MSCs are less immunogenic and can induce tolerance upon transplantation[13]. Moreover, MSCs showed the highest potential for liver regeneration compared with other BM cell subpopulations [14].

Little is known about the underlying molecular mechanisms that link MSCs to the targeted inhibition of tumor cells. Despite their distinct origins, stem cells and tumor cells share many characteristics[15,16]. In particular, they have similar signaling pathways that regulate self-renewal and differentiation[17-20]. The Wnt signaling pathway has been widely investigated in recent years. It has an important role in stem cell self-renewal and differentiation, and aberrant activation of the Wnt signaling pathway has been implicated in human tumor progression[21]. This has raised the possibility that the tightly regulated self-renewal process that is mediated by Wnt signaling in stem cells and progenitor cells may be subverted in cancer cells to allow malignant proliferation. Wnt signaling regulates genes that are involved in cell metabolism, proliferation, cell-cycle regulation and apoptosis[22].
The present work aimed at evaluating the tumor suppressive effects of MSCs on the in vivo progression of $\mathrm{HCC}$, and to investigate the possible role of Wnt signaling in tumor tissues by assessing the gene expression profile of some of the Wnt signaling target genes:cyclin $D$, PCNA, survivin, $\beta$-catenin.

\section{Methods}

Ninety albino female rats inbred strain (Cux1: HEL1) of matched age and weight (6 months-1 year \& 120-150 $\mathrm{gm})$ were included in the study. Animals were inbred in the experimental animal unit, Faculty of Medicine, Cairo University. Rats were maintained according to the standard guidelines of Institutional Animal Care and Use Committee and after Institutional Review Board approval. Animals were fed a semi-purified diet that contained (gm/kg): 200 casein, 555 sucrose, 100 cellulose, 100 fat blends, 35 vitamin mix, and 35 mineral mix [23]. They were divided equally into the following groups: $1^{\text {st }}$ control rats group, $2^{\text {nd }}$ group received MSCs only ( $3 \times 10^{6}$ cells intravenously), $3^{\text {rd }}$ group received MSCs solvent, $4^{\text {th }}$ HCC group induced by diethyl-nitroseamine (DENA) and $\mathrm{CCl}_{4}, 5^{\text {th }}$ group received MSCs after induction of $\mathrm{HCC}, 6^{\text {th }}$ group received MSCs before induction of $\mathrm{HCC}$.

\section{Preparation of BM-derived MSCs}

Bone marrow was harvested by flushing the tibiae and femurs of 6-week-old white albino male rats with Dulbecco's modified Eagle's medium (DMEM, GIBCO/BRL) supplemented with $10 \%$ fetal bovine serum (GIBCO/ BRL). Nucleated cells were isolated with a density gradient [Ficoll/Paque (Pharmacia)] and resuspended in complete culture medium supplemented with $1 \%$ penicillinstreptomycin (GIBCO/BRL). Cells were incubated at $37^{\circ}$ $\mathrm{C}$ in $5 \%$ humidified $\mathrm{CO}_{2}$ for 12-14 days as primary culture or upon formation of large colonies. When large colonies developed (80-90\% confluence), cultures were washed twice with phosphate buffer saline (PBS) and the cells were trypsinized with $0.25 \%$ trypsin in $1 \mathrm{mM}$ EDTA (GIBCO/BRL) for 5 min at $37^{\circ} \mathrm{C}$. After centrifugation, cells were resuspended with serum-supplemented medium and incubated in $50 \mathrm{~cm}^{2}$ culture flasks (Falcon). The resulting cultures were referred to as firstpassage cultures[24]. On day 14, the adherent colonies of cells were trypsinized, and counted. Cells were identified as being MSCs by their morphology, adherence, and their power to differentiate into osteocytes[25] and chondrocytes[26]. Differentiation into osteocytes was achieved by adding 1-1000 nM dexamethasone, 0.25 $\mathrm{mM}$ ascorbic acid, and 1-10 $\mathrm{mM}$ beta-glycerophosphate to the medium. Differentiation of MSCs into osteoblasts was achieved through morphological changes, Alzarin red staining of differentiated osteoblasts and RT-PCR 
gene expression of osteonectin in differentiated cells. Differentiation into chondrocyte was achieved by adding $500 \mathrm{ng} / \mathrm{mL}$ bone morphogenetic protein-2 (BMP-2; R\&D Systems, USA) and $10 \mathrm{ng} / \mathrm{ml}$ transforming growth factor $\beta 3$ (TGF 33 ) (Peprotech, London) for 3 weeks[26]. In vitro differentiation into chondrocytes was confirmed by morphological changes, Alcian blue staining of differentiated chondrocytes and RT-PCR of Collagen II gene expression in cell homogenate. Total RNA was isolated from the differentiated MSCs using Trizol (Invitrogen, USA). RNA concentrations were measured by absorbance at $260 \mathrm{~nm}$ with a spectrophotometer, and $2 \mu \mathrm{g}$ total RNA was used for reverse transcription using Superscript II reverse transcriptase (Invitrogen, USA). The cDNA was amplified using Taq Platinum (Invitrogen, USA). Osteonectin gene and collagen (II) primers used were designed according to the following oligonucleotide sequence: sense, 5'-GTCTTCTAGCTTCTG GCTCAGC-3'; antisense,5'-GGAGAGCTGCTTCTCC CC-3' (uniGene Rn.133363) and sense, 5'-CCGTGCTTC TCAGAACATCA-3'; antisense, 5'-CTTGCCCCATT CATTTGTCT-3' (UniGene Rn.107239). The RNA templates were amplified at 33 to 45 cycles of $94^{\circ} \mathrm{C}$ (30 sec), $58^{\circ} \mathrm{C}$ to $61^{\circ} \mathrm{C}(30 \mathrm{sec}), 72^{\circ} \mathrm{C}(1 \mathrm{~min})$, followed with $72^{\circ} \mathrm{C}$ for $10 \mathrm{~min}$. PCR products were visualised with ethidium bromide on a $3 \%$ agarose gel. Glyceraldehyde-3-phosphate dehydrogenase (GAPDH) was detected as housekeeping gene to examine the extracted RNA integrity. CD29 gene expression was also detected by RT-PCR as a marker of MSCs [27].

\section{Preparation of HCC Model}

Hepatocarcinogenesis was induced chemically in rats by injection of a single intraperitoneal dose of diethylnitrosamine at a dose of $200 \mathrm{mg} / \mathrm{kg}$ body weight followed by weekly subcutaneous injections of $\mathrm{CCl} 4$ at a dose of 3 $\mathrm{mL} / \mathrm{kg}$ body weight for 6 weeks $[28,29]$. At the planned time animals were sacrificed by cervical dislocations, blood samples and liver tissues were collected for assessment of the following:

1. Histopathological examination of liver tissues.

2 . Gene expressions by qualitative and quantitative real time PCR for the following genes: $\beta$-catenin, PCNA, cyclin $D$ and survivin genes

3. Alpha fetoprotein by ELISA (provided by Diagnostic Systems Laboratories, Inc., Webstar, Texas, USA.)

\section{PCR detection of male-derived MSCs}

Genomic DNA was prepared from liver tissue homogenate of the rats in each group usingWizard ${ }^{\circledR}$ GenomicDNApurification kit (Promega, Madison, WI, USA). The presence or absence of the sex determination region on the $\mathrm{Y}$ chromosome male (sry) gene in recipient female rats was assessed by PCR. Primer sequences for sry gene (forward 5'-CATCGAAGGGTTAAAGTGCCA-3', reverse 5'-ATAGTGTGTAG-GTTGTTGTCC-3') were obtained from published sequences[30,31] and amplified a product of $104 \mathrm{bp}$. The PCR conditions were as follows: incubation at $94^{\circ} \mathrm{C}$ for 4 min; 35 cycles of incubation at $94^{\circ} \mathrm{C}$ for $50 \mathrm{~s}, 60^{\circ} \mathrm{C}$ for $30 \mathrm{~s}$, and $72^{\circ} \mathrm{C}$ for $1 \mathrm{~min}$; with a final incubation at $72^{\circ} \mathrm{C}$ for $10 \mathrm{~min}$. PCR products were separated using $2 \%$ agarose gel electrophoresis and stained with ethidium bromide.

\section{Labeling stem cells with PKH26}

PKH26 is a red fluorochrome. It has excitation (551 nm) and emission $(567 \mathrm{~nm}$ ) characteristics compatible with rhodamine or phycoerythrin detection systems. The linkers are physiologically stable and show little to no toxic side-effects on cell systems. Labeled cells retain both biological and proliferating activity, and are ideal for in vitro cell labeling, in vitro proliferation studies and long term, in vivo cell tracking. In the current work, undifferentiated MSCs cells were labeled with PKH26 according to the manufacturer's recommendations (Sigma, Saint Louis, Missouri, USA). Cells were injected intravenously into rat tail vein. After one month, liver tissue was examined with a fluorescence microscope to detect the cells stained with PKH26. Fluorescence was only detected in the 5 th rat group.

\section{Real-time quantitative analyses for $\beta$-catenin,PCNA,cyclin $D$ and survivin genes expression}

Total RNA was extracted from liver tissue homogenate using RNeasy purification reagent (Qiagen, Valencia, CA). cDNA was generated from $5 \mu \mathrm{g}$ of total RNA extracted with $1 \mu \mathrm{l}(20 \mathrm{pmol})$ antisense primer and 0.8 $\mu \mathrm{l}$ superscript AMV reverse transcriptase for $60 \mathrm{~min}$ at $37^{\circ} \mathrm{C}$. Quantitation of gene expression was conducted using universal probe library sets based real time PCR (Roche diagnostics). Selection of genes specific probes and primers were done using the online ProbeFinder software and the real time PCR design assay of Roche Diagnostics found their website: http://www.universalprobelibrary.com, Hypoxanthine phosphoribosy-ltransferase 1 (Hprt1) was used as a positive control house keeping gene. FastStart Universal Probe Master mix was used in LightCycler ${ }^{\circledR} 480$ Instrument (Roche Applied Science, Indianapolis, USA). Briefly, in the LightCycler ${ }^{\circledR}$ 480 , a total reaction volume of $20 \mu \mathrm{l}$ was prepared, of which $2 \mu$ l of starting RNA material was included for RT-PCR, a final concentration of $0.5 \mu \mathrm{M}$ of each forward and reverse primer and $0.2 \mu \mathrm{M}$ of the TaqMan probe was used. Cycling conditions involve reverse transcription at $50^{\circ} \mathrm{C}$ for $30 \mathrm{~min}$; enzyme activation at $95^{\circ} \mathrm{C}$ for $15 \mathrm{~min}$, followed by 50 cycles of $95^{\circ} \mathrm{C}$ for $10 \mathrm{sec}$ and $60^{\circ} \mathrm{C}$ for 60 sec. LightCycler ${ }^{\circledR} 480 \mathrm{RT}-\mathrm{PCR}$ data were analyzed using LightCycler1.2 version 3.5 software using 
the second derivative maximum method. Successfully amplified targets are expressed in Ct values, or the cycle at which the target amplicon is initially detected above background fluorescence levels as determined by the instrument software. Each sample RT-PCR was performed minimally in duplicate, and the mean $\mathrm{Ct}$ value with standard deviation reported.

Primer sequences:

1-Beta-Catenin:

- left: acagcactccatcgaccag

- right: ggtcttccgtctccgatct

2-CyclinD:

- left: ttcctgcaatagtgtctcagttg

- right: aaagggctgcagctttgtta

3-PCNA:

- left: gaactttttcacaaaagccactc

- right: gtgtcccatgtcagcaatttt

4-Survivin:

- left: gagcagctggctgcctta

- right: ggcatgtcactcaggtcca

\section{Analysis of liver Pathology}

Liver samples were collected into PBS and fixed overnight in $40 \mathrm{~g} / \mathrm{Lparaformaldehyde} \mathrm{in} \mathrm{PBS}$ at $4^{\circ} \mathrm{C}$. Serial 5$\mu \mathrm{m}$ sections of the right lobes of the livers were stained with hematoxylin and eosin (HE) and were examined histopathologically.

\section{Results}

\section{MSCs culture and identification}

Isolated and cultured undifferentiated MSCs reached 70$80 \%$ confluence at 14 days (Figure 1). In vitro osteogenic and chondrogenic differentiation of MSCs were confirmed by morphological changes and special stains (Figure $2 \mathrm{a}, \mathrm{b}$ and Figure $3 \mathrm{a}, \mathrm{b}$ respectively) in addition to gene expression of osteonectin and collagen II (Figure $4 \mathrm{a} \& 4 \mathrm{~b}$ ) and GADPH (Figure 4c).

Histopathology of liver tissues of the animals that received DENA and CCl4 only showed cells with neoplastic changes, anaplastic carcinoma cells, characterized

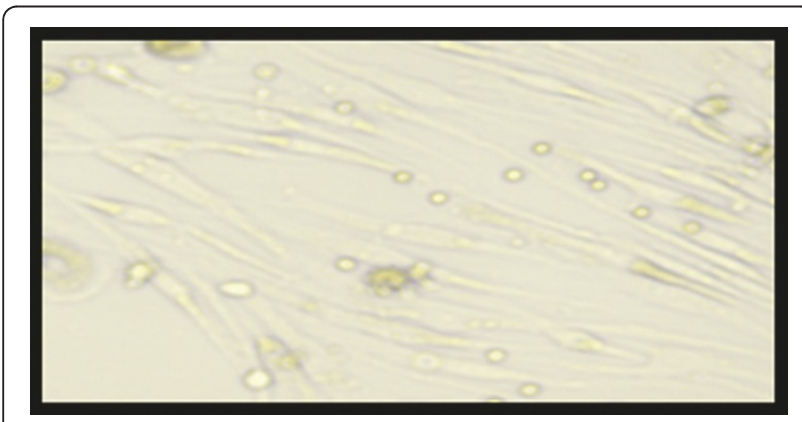

Figure 1 Undifferentiated mesenchymal stem cells after 2 weeks in culture. $(\times 20)$ by large cells with eosinophilic cytoplasm, large hyperchromatic nuclei and prominent nucleoli (Figure 5) and macroregenerative nodules typeII (borderline nodules) with foci of large and small cell dysplasia (Figure 6). Improvement of histopathological picture after the administration of MSCs into rats with HCC is demonstrated in figure(7); with minimal reversible liver cell damage in form of ballooning degeneration, areas of cell drop out filled with stem cells, normal areas with sinusoidal dilatation and congestion and absence of fibrous thickening of portal tracts, inflammation, dysplasia and absence of regenerative nodules. Figure (8) shows MSCs labeled with PKH26 fluorescent dye detected in the hepatic tissue, confirming that these cells homed into the liver tissue. Data obtained from the group which received MSCs only and the one which received MSCs solvent were similar to data obtained from healthy controls. On the other hand, HCC rat group and the rat group injected with stem cells prior to induction of HCC (the prophylactic group) showed significant increase in gene expression of all four genes when compared to controls $(\mathrm{p}<0.05)$ (Figure 9), whereas no significant difference in the gene expression was detected in liver tissues of MSCs-treated HCC rats and control group. As regards serum levels of alpha fetoprotein (Figure 10), as well as ALT and AST (Figure 11); significant increase was found in $\mathrm{HCC}$ and the prophylactic group $(\mathrm{p}<0.05)$, whereas no significant difference was detected in the $\mathrm{HCC}$ rats group treated with MSCs when compared to the control group.

\section{Discussion}

Hepatocellular carcinoma $(\mathrm{HCC})$ is considered as a disease of dysfunction of the stem cells [32]. Stem cells and tumor cells share similar signaling pathways that regulate self-renewal and differentiation, including the Wnt, Notch, Shh and BMP pathways that determine the diverse developmental fates of cells [17-20,33,34]. Therefore, understanding these signaling cascades may provide insights into the molecular mechanisms that underlie stemness and tumorigenesis. In the present study, histopathological examination of liver tissues of the animals group that received DENA and CCl4 was the only one which revealed development of HCC (Figure 1,2). On the other hand, administration of MSCs into rats after induction of experimental HCC led to improvement of histopathological picture with minimal reversible liver cell damage in form of ballooning degeneration, areas of cell drop out filled with stem cells, normal areas with sinusoidal dilatation and congestion and absence of fibrous thickening of portal tracts, inflammation, dysplasia and regenerative nodules. These results reinforce the suggestion of previous studies using animal models which indicated that mesenchymal cells would 


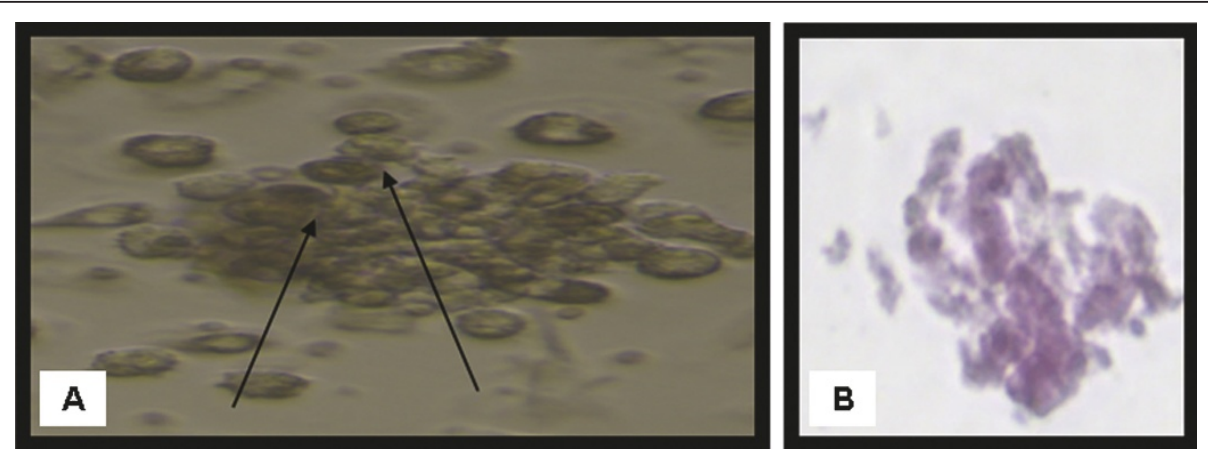

Figure 2 Morphological and histological staining of differentiated BM-MSCs into osteoblasts. (A) (×20) Arrows for differentiated MSCs osteoblasts after addition of growth factors. (B) (×200) Differentiated MSCs into osteoblasts stained with Alizarin red stain.

be more useful for liver regeneration [35-37], as well as the studies which drew attention to the potential of MSCs in regenerative medicine [38].

MSCs were identified by detection of CD29 surface marker, their fusiform shape, adherence, and their ability to differentiate into osteocytes and chondrocytes. Homing of MSCs in liver was confirmed through detection of $\mathrm{Y}$ chromosome-containing cells in samples from female recipients of bone marrow cells from male donors, as well as the detection of MSCs labeled with PKH26(Figure 4). Experimental findings in animal models suggest that the induction of parenchymal damage is a prerequisite for successful homing and repopulation with stem cells $[39,40]$. Molecular mechanisms underlying stem cells mobilization and homing into the injured liver are still poorly understood[41]. However, potential factors and leading pathways have been characterized in these processes, such as the Stromal Cell-Derived Factor-1 (SDF-1)/CXCR4 axis, the proteolytic enzymes matrix metalloproteinases (MMPs), the hepatocyte growth factor (HGF) and the stem cell factor (SCF). The chemokine Stromal Cell-Derived Factor-1 (SDF-1) is a powerful chemo-attractant of hepatic stem cells (HSCs) [42] which plays a major role in the homing, migration, proliferation, differentiation and survival of many cell types of human and murine origin [43]. It is expressed by various bone marrow stromal cell types and epithelial cells in many normal tissues, including the liver [44]. SDF-1 carries on its role through the CXCR4 receptor, a G-protein coupled receptor, expressed on CD34+ hematopoietic stem cells, mononuclear leucocytes and numerous stromal cells $[45,46]$. Kollet and co-workers [47] also showed that CCl4-induced liver injury (which was the case in the present study)resulted in increased activity of the enzyme MMP-2 and emergence of MMP9 in the liver of NOD/SCID mice.

As for the mechanisms by which liver regeneration occurs after bone marrow cells transfusion, many mechanisms have been suggested: fusion between hepatocytes and transplanted bone marrow cells has been substantiated as a mechanism by which hepatocytes that carry a bone marrow tag are generated[48], although many studies suggested that cell fusion was not the main mechanism involved in parenchymal repopulation with exogenous cells $[49,50]$. Another mechanism may be that the stem cells provide cytokines and growth factors in their microenvironment that promote hepatocyte functions by paracrine mechanisms [48]. Robert and coworkers[51] stated that the organ microenvironment can modify the response of metastatic tumor cells to therapy and alter the effectiveness of anticancer agents in destroying the tumor cells without producing

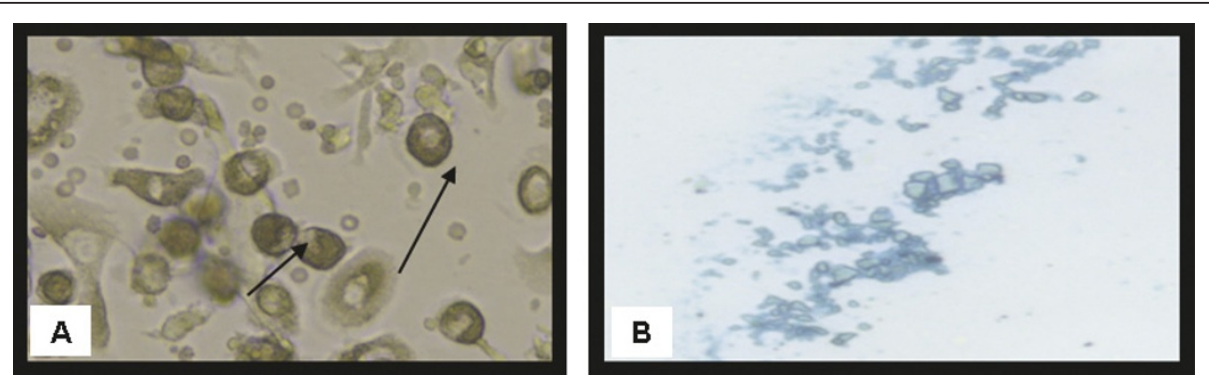

Figure 3 Morphological and histological staining of differentiated BM-MSCs into chondrocytes. (A) (×20) Arrows for differentiated MSCS chondrocytes after addition of growth factors. (B) (×200) Differentiated MSCs into chondrocytes stained with Alcian blue stain. 
1
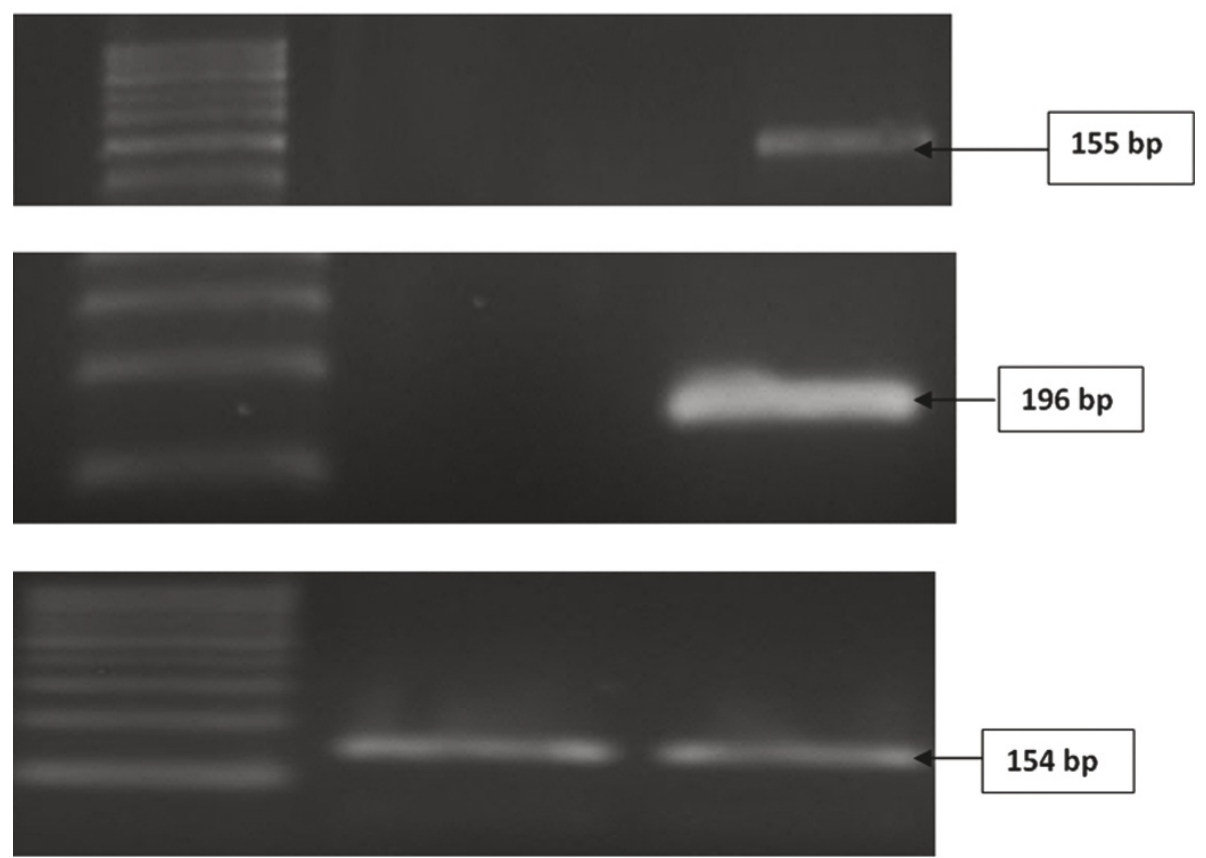

Figure 4 Agrose gel electrophoresis for Molecular identification of undifferentiated and differentiated BM-MSCs: (A) gene expression of osteonectin (B) gene expression of collagen II and (C) gene expression of GAPDH in undifferentiated and differentiated MSCs. (A\&B) Genes expression of osteonectin and collagen II. Lane 1: DNA marker (100, 200, 300 bp). Lane 2:No PCR product for osteonectin and Collagen II genes in undifferentiated MSCs. Lane 3: PCR product for osteonectin and Collagen II genes in differentiated MSCs (C) Gene expression of GAPDH. Lane 1: DNA marker (100, 200, 300 bp). Lane 2: PCR product for GAPDH gene in undifferentiated MSCs

undesirable toxic effects. In his review, Muraca and coworkers[41] pointed out that, the mechanisms underlying the positive effects reported in preliminary trials are complex and most likely do not involve repopulation of liver parenchyma with bone marrow-derived cells but might result from the production of trophic factors by

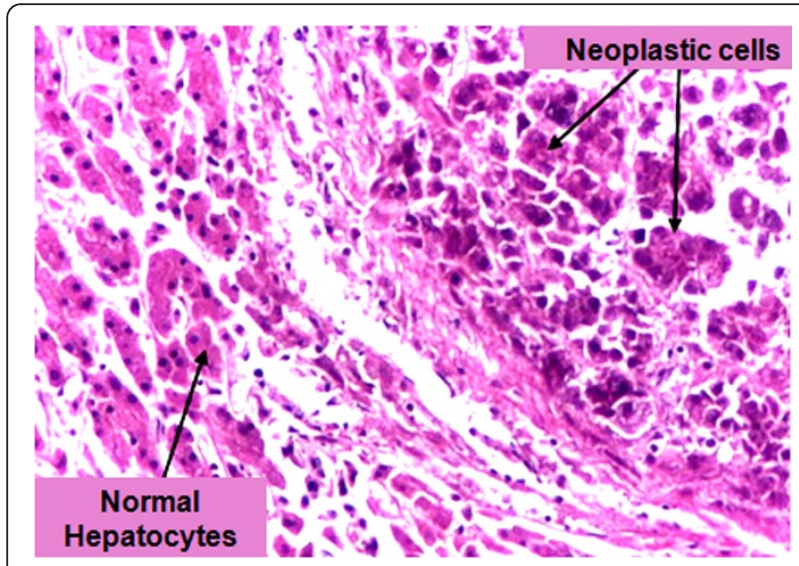

Figure 5 Hepatocellular carcinoma cells. $(\times 400)$ Characterized by large anaplastic carcinoma cells with eosinophilic cytoplasm, large hyperchromatic nuclei and prominent nucleoli. The normal trabecular structure of the liver is distorted. the infused cells, therefore The identification and characterization of the niche are prerequisites for the identification of stem cells and for understanding their behaviour in physiological and pathological conditions. Niches are local tissue microenvironments that maintain and regulate stem cells [52], Livraghi and colleagues [53] stated that the essential role of stem cell microenvironment in preventing carcinogenesis is by providing signals to inhibit proliferation and to promote differentiation. Human MSCs home to sites of Kaposi's sarcoma, and potently inhibit tumor growth in vivo by downregulating Akt activity in tumor cells that are cultured with hMSCs prior to transplantation in animal tumor models [54]. Furthermore, tumor cells may secrete proteins that can activate signaling pathways that facilitate MSCs migration to the tumor site. Direct transdifferentiation of cells is another mechanism of liver regeneration, although it has not been demonstrated [48]. However, recent observations shed some light on possible mechanisms underlying the observed bone marrow-derived cells (BMDC) transdifferentiation driven by injured tissues [55]. As a result of injury, tissues release chemokines attracting circulating BMDC, and can produce microvescicles including RNA, proteins and a variety of signals. The authors provided evidence 


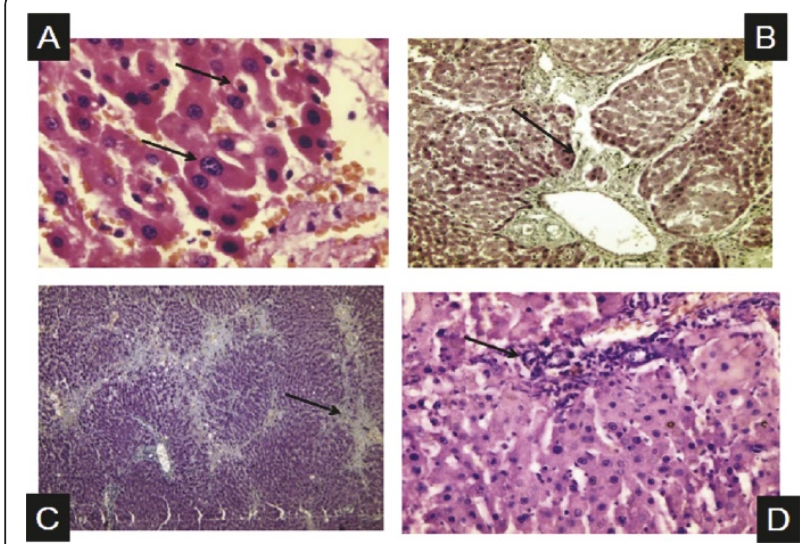

Figure 6 Histopathological picture of liver tissues in experimental HCC. Arrows, A: (×400) Small and large cell dysplasia, B: (×200) Macroregenerative nodules type II (borderline nodules) apparent with foci of small cell dysplasia \& Increased mononuclear cell infiltrates in portal areas, C: $(\times 200)$ Focal fatty change \& confluent necrosis with active septation, D: $(\times 200)$ Portal tract showing increased mononuclear cell infiltrates.

suggesting that these microvescicles are taken up by BMDC and can modify cell phenotype mimicking resident cells in the host tissue. In conclusion, the extensive work performed during the last decade suggests that a series of complex interactions exist between BMDC and injured tissues, including the liver. Microvesicles are mediators of cell reprogramming. Following injury, tissues release chemokines attracting circulating BMDC, and can produce microvesicles including RNA, proteins and a variety of signals. Such microvesicles are taken up

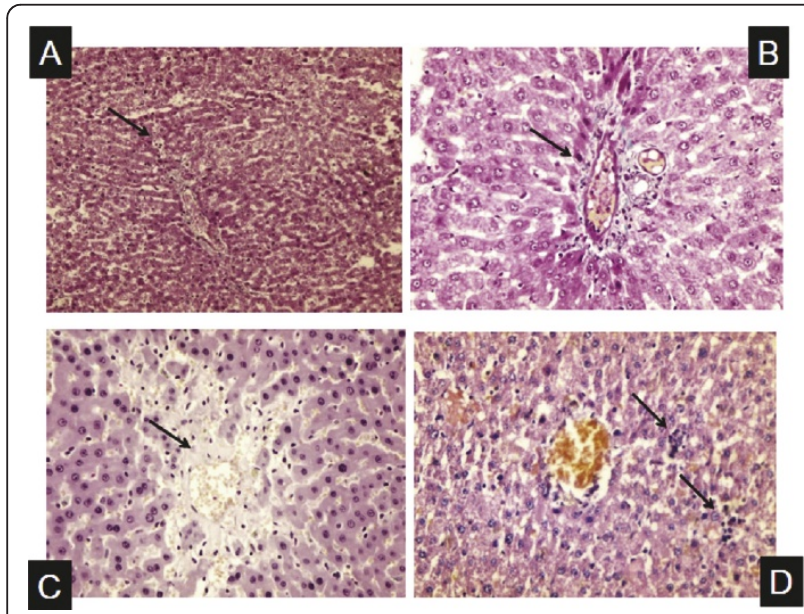

Figure 7 Histopathological picture of liver tissues in rat that received MSCs after induction of hepatoma. Arrows, A: $(\times 200)$ No nodularity \& liver cells and lobules appear normal with ballooning degeneration, B: $(\times 400)$ Normal portal tracts No fibrosis No inflammation, C: $(\times 400)$ Area of cell drop out with stem cells, D: ( $\times 400)$ No nodularity \& liver appears normal, few collections of round to oval stem cells in lobules.

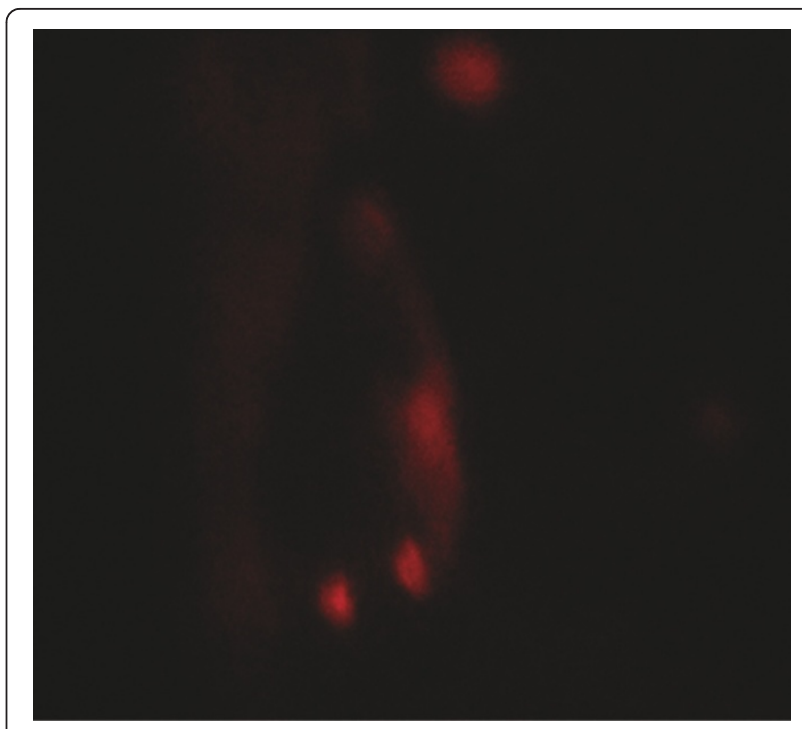

Figure 8 Detection of MSCs labeled with PKH26 fluorescent dye in liver tissue. MSCs labeled with the PKH26 showed strong red autofluorescence after transplantation into rats, confirming that these cells were seeded into the liver tissue.

by BMDC and can modify cell phenotype mimicking the one of resident cells in the host tissue. Insults trigger the release of chemokines from the endothelium inducing adhesion and migration of circulation BMDC into the liver parenchyma. The liver itself can release powerful signals attracting BMDC and probably contributing to remodeling of their morphology and function. These $\mathrm{BMDC}$ in turn can produce molecular signals improving

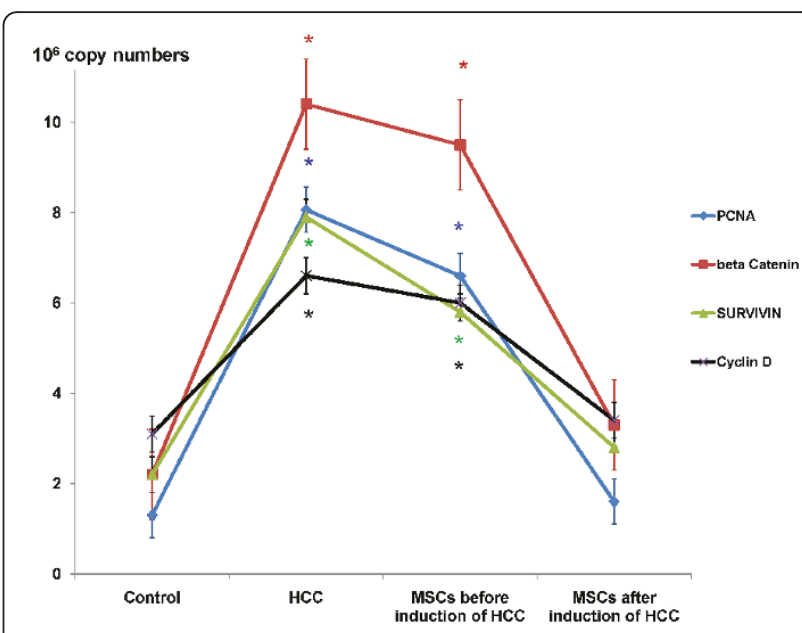

Figure 9 PCNA, Beta catenin, Survivin and Cyclin D genes expression by real time PCR. Results are expressed in $10^{6}$ copy numbers of each gene mRNA (in $100 \mathrm{ng}$ total RNA). Absolute copy numbers was determined by comparing samples with the standard curve generated. The mRNA level of each gene was normalized with the level of HPRT1 mRNA. * Significant difference in comparison to control $(P<0.05)$. 


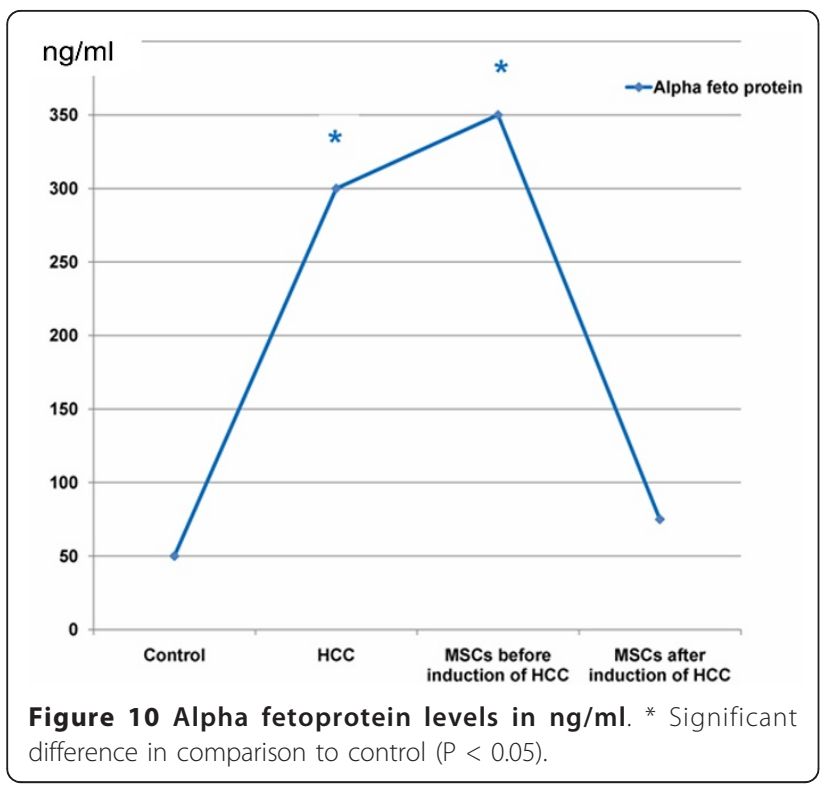

regeneration and function of injured parenchyma. It is to note that, in the present study, administration of MSCs before induction of HCC did not show any tumor suppressive or protective effect. This may be explained by the exposure of MSCs to the chemical carcinogen; DENA and failure of recruitment of MSCs to the liver tissue before exposure to the chemical injury due to the absence of cytokines that recruit MSCs to sites of injury [56]. As regards genetic analysis, results of the present study demonstrated that MSCs downregulated oncogenes expression(Figure 9), where, $\beta$-catenin, PCNA, cyclin $D$ and survivin genes expression was downregulated in liver tissues of MSCs-treated HCC rats which are all involved in $\mathrm{Wnt} / \beta$-catenin pathway;one of the main oncogenic pathways involved in HCC[57]. The decreased serum levels of alpha fetoprotein and liver

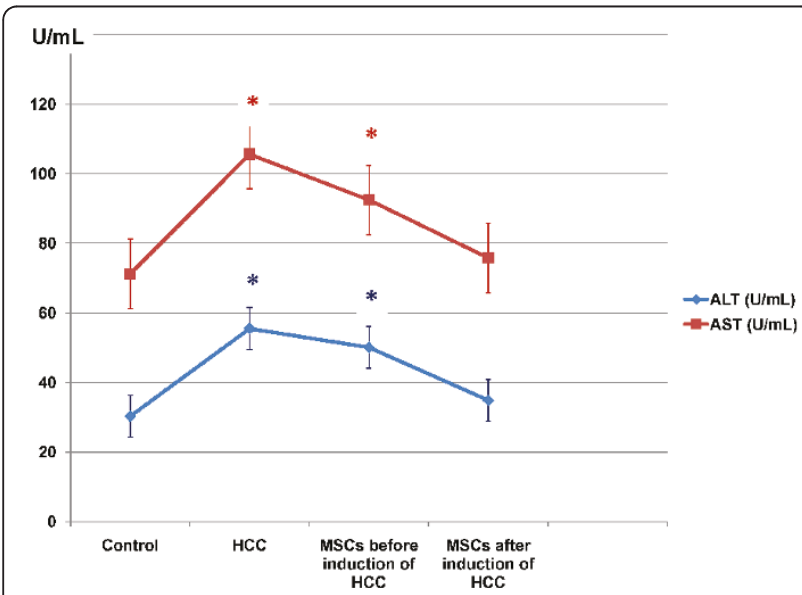

Figure 11 Serum ALT and AST levels in U/ml. * Significant difference in comparison to control $(P<0.05)$. enzymes in the HCC group treated with MSCs indicate the amelioration of the malignant status as well as the liver function of the HCC model.

In recent years, improved knowledge of oncogenic processes and the signaling pathways that regulate tumor cell proliferation, differentiation, angiogenesis, invasion and metastasis has led to the identification of several possible therapeutic targets that have driven the development of molecular targeted therapies. These drugs have showed clinical benefit in patients with various tumor types, including $\mathrm{HCC}[1]$.

A major and early carcinogenic event in the development of HCC seems to be the abnormal regulation of the transcription factor $\beta$-catenin, a key component of the Wnt signaling pathway [58]. In the normal state, the binding of members of a family of soluble cysteine-rich glycoprotein ligands, the Wnts, to members of the Frizzled family of cell-surface receptors results in the activation of the Wnt signaling pathway. Receptor binding activates DSH (downstream effector Dishevelled), which consequently prevents phosphorylation of $\beta$-catenin by glycogen synthase kinase- $3 \beta$ and its subsequent ubiquitination and proteasomal degradation. An ensuing increase in the cytoplasmic concentrations of $\beta$-catenin results in its translocation from the cytoplasm to the nucleus. Once in the nucleus, $\beta$-catenin acts as a co-activator to stimulate the transcription of genes and expression of gene products involved in cell proliferation (e.g: $c-M y c$, Cyclin-D, PCNA), angiogenesis (e.g: VEGF), antiapoptosis (e.g: Survivin) and the formation of extracellular matrix [59].

Interestingly, Schmidt and coworkers[60] suggested that Iqgap 2 acts as a tumor suppressor, and its loss can lead to $\beta$-catenin activation and the development of HCC, and this finding further implicates $\beta$-catenin as a key driver of HCC. Direct mutation of $\beta$-catenin is not the only route through which the Wnt pathway can be aberrantly activated in HCC. In their study, Hoshida and coworkers[61] stated that, from the three subclasses of HCC that had been characterized, two of them showed either increased Wnt pathway activity or increased MYC/AKT pathway activity. In the present study, overexpression of gene of the Wnt signaling molecule; $\beta$-catenin and its downstream targets; PCNA, cyclin $D$ and survivin genes in liver tissue transformed by DENA, together with their downregulation in MSCs treated rats provids evidence that the Wnt signaling pathway is likely to regulate the inhibitory role of MSCs. Similar suggestions were provided by Qiao and coworkers[8]. Also, Zhu and coworkers [62] demonstrated that MSCs have an inhibitory effect on tumor proliferation by identifiing that DKK-1 (dickkopf-1) which was secreted by MSCs, acts as a negative regulator of Wnt signaling pathway and is one of the molecules responsible for the inhibitory effect. 
Also, Wei and coworkers studied the inhibition of Wnt-1-mediated signaling as a potential molecular target in HCC and demonstrated that Wnt-1 was highly expressed in human hepatoma cell lines and a subgroup of human HCC tissues compared to paired adjacent non-tumor tissues. An anti-Wnt-1 antibody dosedependently decreased viability and proliferation of Huh7 and Hep40 cells over-expressing Wnt-1 and harboring wild type $\beta$-catenin, but did not affect normal hepatocytes with undetectable Wnt-1 expression. Apoptosis was also observed in Huh7 and Hep40 cells after treatment with anti-Wnt-1 antibody. In these two cell lines, the anti-Wnt-1 antibody decreased $\beta$-catenin/Tcf4 transcriptional activities, which were associated with down-regulation of the endogenous $\beta$ catenin/Tcf4 target genes $c-M y c$, cyclin $D 1$, and survi$v i n$. They also demonstrated that intratumoral injection of anti-Wnt-1 antibody suppressed in vivo tumor growth in a Huh7 xenograft model, which was also associated with apoptosis and reduced c-Myc,cyclin D1 and survivin expressions [63]. MSCs could upregulate the mRNA expression of cell-cycle negative regulator p21 and apoptosis-associated protease caspase-3, resulting in a G0/G1 phase arrest and apoptotic cell death of tumor cells[64]. They also secrete Dickkopf-1 (DKK-1) to suppress the $\mathrm{Wnt} / \mathrm{b}$-catenin signaling pathway, attenuating the malignant phenotype of tumor cells[65].

However, the effect of human bone marrow derived MSCs on the growth of tumoral cells is controversial. HCC was thought to arise from hepatic stem cells; in their study Ishikawa and colleagues[66], investigated the malignant potential of hepatic stem cells derived from the bone marrow in a mouse model of chemical hepatocarcinogenesis, their results suggested that hepatic stem cells derived from the bone marrow have low malignant potential, at least in their model.

Regarding their potential therapeutic use in neoplastic diseases, some studies have suggested that adoptively transferred MSCs could favor tumor engraftment and progression in vivo [67]. The deleterious effects could derive from different MSCs characteristics. MSCs specifically migrate toward sites of active tumorigenesis, where they could integrate the specialized tumor niche, contribute to the development of tumor-associated fibroblasts and myofibroblasts[68], stimulate angiogenesis[69], and promote the growth and drug resistance of both solid tumors and hematological malignancies[70]. On the contrary, Secchiero and coworkers[71] stated that although MSCs release several pro-angiogenic cytokines and promoted the migration of endothelial cells, they found that MSCs when directly cocultured with endothelial cells, significant induction of endothelial cell apoptosis occured. In this respect, their findings are in agreement with those of other authors who have demonstrated that MSCs under certain circumstances might exert anti-angiogenic activity in highly vascularized tumours[72,73], as well as in normal endothelial cell cultures in vitro. Otsu and coworkers[73] stated that direct MSCs inoculation into subcutaneous melanomas in an in vivo tumor model, induced apoptosis and abrogated tumor growth. These findings showed for the first time that at high numbers, MSCs are potentially cytotoxic and that when injected locally in tumor tissue they might be effective antiangiogenesis agents suitable for cancer therapy. These controversies can be attributed to many factors such as ratio of MSCs to cancer cells, nature of tumour cells and cancer stem cells, integrity of immune system, number of stem cell passages and site of injection; all can affect the outcome of MSCs use in malignancy. Therefore, the "lack of reproducibility" pointed out by some authorities [74] is at least partially due to large experimental differences in published work. There is thus obvious need for a joined effort by researchers in the field in order to standardize models and procedures both in vitro and in vivo [75].

Several novel findings regarding the role of MSCs in cancer development and/or therapy are summarized from several studies [76,77]: MSCs can behave as potent antigen-presenting cells (APCs) and could be exploited as a new therapeutic tool in cancer therapy in order to amplify immune responses against tumor-specific antigens [12]. Lu and coworkers[78] demonstrated that MSCs had potential inhibitory effects on tumor cell growth in vitro and in vivo without host immunosuppression, by inducing apoptotic cell death and G0/G1 phase arrest of cancer cells.

On the basis of the previously reported preclinical data, BM cells seem to facilitate liver regeneration mainly by a microenvironment modulation, which is likely to be transitory. In such a case, multiple treatments would presumably be required to achieve significant and lasting clinical results; technical issues that need to be addressed regard the surface antigens used for MSCs purification, the route of delivery, the amount of infused cells and the timing of infusions[79].

\section{Conclusions}

In conclusion, the present findings demonstrate that MSCs have tumor suppressive effects in chemically induced hepatocarcinogenesis as evidenced by down regulation of Wnt signaling target genes concerned with antiapoptosis, mitogenesis, cell proliferation and cell cycle regulation. Therefore, Wnt signaling might be considered as an important pathway in MSCs-mediated targeting of tumor inhibition. Further studies are recommended regarding the study of different molecular signaling pathways and the precise biologic characteristics of MSCs. 
Thorough evaluation of MSCs potential risks versus benefits in malignancy still need to be explored.

\section{Acknowledgements}

This work was financially supported by a grant from the charity foundation of the late Professor Dr. Yassin Abdel Ghaffar and Wife (HCC GRANT). Special thanks to Professor Dr. Tawhida Yassin Abdel Ghaffar; Professor of Pediatric Hepatology, Faculty of Medicine, Ain Shams University.

\section{Author details}

'Unit of Biochemistry and Molecular Biology (UBMB), Department of Medical Biochemistry, Faculty of Medicine, Cairo University, Cairo, Egypt. ${ }^{2}$ Department of Medical Biochemistry, Faculty of Medicine, Ain Shams University, Cairo, Egypt. ${ }^{3}$ Department of Pathology, Faculty of Medicine, Cairo University, Cairo, Egypt.

\section{Authors' contributions}

MTA, MFE, HA participated in the design of the study and revised it critically; $H F, N R, L R$, DS, AH, FT carried out the performance the study; SM carried out the analysis of liver pathology; HF, AH performed analysis and interpretation of data and HF, AH drafted the manuscript. All authors read and approved the final manuscript.

\section{Competing interests}

The authors declare that they have no competing interests.

Received: 18 January 2011 Accepted: 5 May 2011 Published: 5 May 2011

\section{References}

1. Whittaker $S$, Marais $R$, Zhu AX: The role of signaling pathways in the development and treatment of hepatocellular carcinoma. Oncogene 2010, 29:4989-5005.

2. Seeff $L B$, Hoofnagle $J H$ : Epidemiology of hepatocellular carcinoma in areas of low hepatitis B and hepatitis C endemicity. Liver cancer in areas of low hepatitis frequency. Oncogene 2006, 25:3771-3777.

3. Mizokami M, Tanaka Y: Tracing the evolution of hepatitis $\mathrm{C}$ virus in the United States, Japan, and Egypt by using the molecular clock. Clin Gastroenterol Hepatol 2005, 3:S82-S85.

4. Abdel Aziz MT, Abdel Aziz M, Fouad HH, et al: Interferon-gene therapy prevents aflatoxin and carbon tetrachloride promoted hepatic carcinogenesis in rats. Int J Mol Med 2005, 15:21-26.

5. Coverdale SA, Khan MH, Byth K, et al: Effects of Interferon Treatment Response on Liver Complications of Chronic Hepatitis C: 9-year FollowUp Study. Am J Gastroenterol 2004, 99(4):636-44.

6. Miyake Y, Takaki A, Iwasaki Y, Yamamoto K: Meta-analysis: interferon-alpha prevents the recurrence after curative treatment of hepatitis $C$ virusrelated hepatocellular carcinoma. J Viral Hepatitis 2010, 17:287-292.

7. Levicar N, Dimarakis I, Flores C, Tracey J, Gordon MY, Habib NA: Stem cells as a treatment for chronic liver disease and diabetes. Handb Exp Pharmacol 2007, , 180: 243-62.

8. Qiao $L, X u Z$, Zhao Z, et al: Suppression of tumorigenesis by human Mesenchymal Stem Cells in a hepatoma model. Cell Res 2008, 18:500-507.

9. Nakamizo A, Marini F, Amano T, et al: Human bone marrow derived mesenchymal stem cells in the treatment of gliomas. Cancer Res 2005, 65:3307-3318.

10. Livraghi T, Meloni F, Frosi A: Treatment with stem cell differentiation stage factors of intermediate-advanced hepatocellular carcinoma: an open randomized clinical trial. Oncol Res 2005, 15:399-408.

11. Ringden O, Le Blanc K: Allogeneic hematopoietic stem cell transplantation: state of the art and new perspectives. APMIS 2005, 113:813-830.

12. Pommey S, Galipeau J: The use of mesenchymal stromal cells in oncology and cell therapy. Bull Cancer 2006, 93:901-907.

13. Lysy PA, Campard D, Smets F, et al: Stem cells for liver tissue repair: current knowledge and perspectives. World Journal of Gastroenterology 2008, 14(6):864-875.

14. Cho KA, Ju SY, Cho SJ, et al: MMesenchymal stem cells showed the highest potential for the regeneration of injured liver tissue compared with other subpopulations of the bone marrow. Cell Biology International 2009, 33(7):772-777.

15. Menon $L G$, Picinich $S$, Koneru R, et al: Differential gene expression associated with migration of mesenchymal stem cells to conditioned medium from tumor cells or bone marrow cells. Stem Cells 2007, 25:520-528.

16. Reya T, Morrison SJ, Clarke MF, et al: Stem cells, cancer, and cancer stem cells. Nature 2001, 414:105-111.

17. Reya T, Clevers H: Wnt signalling in stem cells and cancer. Nature 2005, 434:843-850

18. Willert K, Jones KA: Wnt signalling: is the party in the nucleus? Genes Dev 2006, 20:1394-1404.

19. Raida M, Heymann AC, Gunther C, et al: Role of bone morphogenetic protein 2 in the crosstalk between endothelial progenitor cells and mesenchymal stem cells. Int J Mol Med 2006, 18:735-739.

20. Miele L, Miao H, Nickoloff BJ: NOTCH signalling as a novel cancer therapeutic target. Curr Cancer Drug Targets 2006, 6:313-323.

21. Moon RT, Kohn AD, De Ferrari GV, et al: $\mathrm{WNT}$ and beta-catenin signalling: diseases and therapies. Nat Rev Genet 2004, 5:691-701.

22. Yang $F$, Zeng $Q$, Yu G, et al: Wnt/beta-catenin signalling inhibits death receptor-mediated apoptosis and promotes invasive growth of HNSCC. Cell Signal 2006, 18:679-87.

23. Abdel Aziz MT, El-Asmar MF, Mostafa T, et al: Effect of hemin and carbon monoxide releasing molecule (CORM-3) on cGMP in rat penile tissue. $\rfloor$ Sex Med 2008, 5:336-43.

24. Abdel Aziz MT, Atta HM, Mahfouz S, et al: Therapeutic potential of bone marrow-derived mesenchymal stem cells on experimental liver fibrosis. Clin Biochem 2007, 40:893-899.

25. Jaiswal N, Haynesworth S, Caplan A, Bruder S: Osteogenic differentiation of purified, culture-expanded human mesenchymal stem cells in vitro. $J$ Cell Biochem 1997, 64:295-312.

26. Seo MS, Jeong YH, Park JR, et al: Isolation and characterization of canine umbilical cord blood-derived mesenchymal stem cells. J Vet Sci 2009, 10:181-7.

27. Munoz-Fernandez R, Blanco FJ, Frecha C, et al: Follicular dendritic cells are related to bone marrowstromal cell progenitors and to myofibroblasts. J Immunol 2006, 177:280-9.

28. Dakshayani KB, Subramanian P, Manivasagam T, Essa MM, Manoharan S: Melatonin modulates the oxidant-antioxidant imbalance during $\mathrm{N}$ nitrosodiethylamine induced hepatocarcinogenesis in rats. J Pharm Pharm Sci 2005, 8(2):316-21.

29. Sundaresan S, Subramanian P: S-Allylcysteine inhibits circulatory lipid peroxidation and promotes antioxidants in N-nitrosodiethylamineinduced carcinogenesis. Pol J Pharmacol 2003, 55:37-42.

30. Wu GD, Tuan TL, Bowdish ME, Jin YS, Starnes VA, Cramer DV, et al: Evidence for recipient derived fibroblast recruitment and activation during the development of chronic cardiac allograft rejecion. Transplantation 2003, 76:609-14.

31. An J, Beauchemin N, Albanese J, Abney TO, Sullivan AK: Use of a rat CDNA probe specific for the $\mathrm{Y}$ chromosome to detect male-derived cells. J Androl 1997, 18:289-93.

32. Fangjun $Y$, Wenbo $Z$, Can $Z$, et al: Expression of Oct4 in HCC and modulation to wnt $/ \beta$-catenin and TGF- $\beta$ signal pathways. Mol Cell Biochem 2010, 343(1-2):155-62.

33. Lindvall C, Evans NC, Zylstra CR, et al: The WNT signaling receptor, LRP5, is required for mammary ductal stem cell activity and WNT1-induced tumorigenesis. J Biol Chem 2006, 281:35081-35087.

34. Androutsellis-Theotokis A, Leker RR, Soldner F, et al: Notch signalling regulates stem cell numbers in vitro and in vivo. Nature 2006, 442:823-826.

35. Sakaida I, Terai S, Yamamoto N, et al: Transplantation of bone marrow cells reduces CCl4-induced liver fibrosis in mice. Hepatology 2004, 40:1304-1311.

36. Terai S, Sakaida I, Nishina H, et al: Lesson from the GFP/CCI4 modeltranslational research project: The development of cell therapy using autologous bone marrow cells in patients with liver cirrhosis. $J$ Hepatobiliary Pancreat Surg 2005, 12:203-207.

37. Yamamoto $N$, Terai $S$, Ohata $S$, et al: A subpopulation of bone marrow cells depleted by a novel antibody, anti-Liv8, is useful for cell therapy to repair damaged liver. Biochem Biophys Res Commun 2004, 313:1110-1118. 
38. Jiang $Y$, Jahagirdar BN, Reinhardt RL, et al: Pluripotency of mesenchymal stem cells derived from adult marrow. Nature 2002, 418:41-49.

39. Schwartz RE, Reyes $M$, Koodie $L$, et al: Multipotent adult progenitor cells from bone marrow differentiate into functional hepatocyte-like cells. $J$ Clin Invest 2002, 109:1291-302.

40. Krause DS, Theise ND, Collector MI, et al: Multi-organ, multi-lineage engraftment by a single bone marrow-derived stem cell. Cell 2001, 105:369-77.

41. Muraca M: Evolvingconcepts in cell therapy of liver disease and current clinical perspectives. Digestive and Liver Disease 2011, 43:180-187.

42. Aiuti A, Webb IJ, Bleul C, et al: The chemokine SDF-1 is a chemoattractan for human $\mathrm{CD} 34+$ hematopoietic progenitor cells and provides a new mechanism to explain the mobilization of CD34+ progenitors to peripheral blood. J ExpMed 1997, 185:111-20.

43. Dalakas E, Newsome PN, Harrison DJ, et al: Hematopoietic stem cell trafficking in liver injury. FASEB J 2005, 19:1225-31.

44. Muraca M, Gerunda G, Neri D, et al: Hepatocyte transplantation as a treatment for glycogen storage disease type 1a. Lancet 2002, 359:1528.

45. Kollet O, Petit I, Kahn J, et al: Human CD34(+)CXCR4(-) sorted cells harbor intracellular CXCR4, which can be functionally expressed and provide NOD/SCID repopulation. Blood 2002, 100:2778-86.

46. Nagasawa T, Tachibana K, Kawabata K: A CXC chemokine SDF-1/PBSF: a ligand for a HIV coreceptor, CXCR4. Adv Immunol 1999, 71:211-28.

47. Kollet $O$, Shivtiel $S$, Chen YQ, et al: HGF, SDF-1, and MMP-9 are involved in stress-induced human CD34+stem cell recruitment to the liver. J Clin Invest 2003, 112:160-9.

48. Snorri ST, Grisham Joe W: Hematopoietic Cells as Hepatocyte Stem Cells: A Critical Review of the Evidence. Hepatology 2006, 43:2-8.

49. Jang YY, Collector MI, Baylin SB, et al: Hematopoietic stem cells convert into liver cells within days without fusion. Nat Cell Biol 2004, 6:532-9.

50. Muraca M, Ferraresso C, Vilei MT, et al: Liver repopulation with bone marrow derived cells improves the metabolic disorder in the Gunn rat. Gut 2007, 56:1725-35

51. Langley R, Fidler I: Tumor Cell-Organ Microenvironment Interactions in the Pathogenesis of Cancer Metastasis. Endocrine Reviews 2007, 28:297-321.

52. Morrison SJ, Spradling AC: Stem cells and niches: mechanisms that promote stem cell maintenance throughout life. Cell 2008, 132:598-611.

53. Livraghi $T$, Meloni $F$, Frosi A: Treatment with stem cell differentiation stage factors of intermediate-advanced hepatocellular carcinoma: an open randomized clinical trial. Oncol Res 2005, 15:399-408.

54. Khakoo AY, Pati S, Anderson SA, et al: Human mesenchymal stem cells exert potent antitumorigenic effects in a model of Kaposi's sarcoma. $J$ Exp Med 2006, 203:1235-1247.

55. Aliotta JM, Sanchez-Guijo FM, Dooner GJ, et al: Alteration of marrow cell gene expression, protein production, and engraftment into lung by lungderived microvesicles: a novel mechanism for phenotype modulation. Stem Cells 2007, 25:2245-56.

56. Abdel Aziz MT, Atta H, Roshdy NK, et al: Role of SDF-1/CXCR4 Axis in Stem Cell Homing in the Mouse Model of Induced Lung Fibrosis. Int J Biotech Biochem 2010, 6(4):625-644.

57. Parkin DM: The global health burden of infection-associated cancers in the year 2002. Int J Cancer 2006, 118:3030-3044.

58. De La CA, Romagnolo B, Billuart $P$, et al: Somatic mutations of the betacatenin gene are frequent in mouse and human hepatocellular carcinomas. Proc Acad Sci USA Natl 1998, 95:8847-8851.

59. Avila MA, Berasain C, Sangro B, Prieto J: New therapies for hepatocellular carcinoma. Oncogene 2006, 25:3866-3884.

60. Schmidt VA, Chiariello CS, Capilla E, Miller F, Bahou WF: Development of hepatocellular carcinoma in Iqgap2-deficient mice is IQGAP1 dependent. Mol Cell Biol 2008, 28:1489-1502.

61. Hoshida Y, Nijman SM, Kobayashi M, et al: Integrative transcriptome analysis reveals common molecular subclasses of human hepatocellular carcinoma. Cancer Res 2009, 69:7385-7392.

62. Zhu $Y$, Sun $Z$, Han Q, et al: Human mesenchymal stem cells inhibit cancer cell proliferation by secreting DKK-1. Leukemia 2009, 23(5):925-33.

63. Wei W, Chua M, Grepper S, So SK: Blockade of Wnt-1 signaling leads to anti-tumor effects in hepatocellular carcinoma cells. Mol Cancer 2009, $8: 76$.

64. Djouad F, Bony C, Apparailly F, et al: Earlier onset of syngeneic tumors in the presence of mesenchymal stem cells. Transplantation 2006, 82:1060.
65. Etheridge SL, Spencer GJ, Heath DJ, et al: Expression profiling and functional analysis of wnt signaling mechanisms in mesenchymal stem cells. Stem Cells 2004, 22:849.

66. Ishikawa $\mathrm{H}$, Nakao $\mathrm{K}$, Matsumoto $\mathrm{K}$, et al: Bone marrow engraftment in a rodent model of chemical carcinogenesis but no role in the histogenesis of hepatocellular carcinoma. Gut 2004, 53:884-889.

67. Guest I, Ilic Z, Ma J, et al: Direct and indirect contribution of bone marrow derived cells to cancer. Int J Cancer 2010, 126(10):2308-18

68. Spaeth EL, Dembinski JL, Sasser AK, et al: Mesenchymal stem cell transition to tumor-associated fibroblasts contributes to fibrovascular network expansion and tumor progression. PLoS One 2009, 4:e4992.

69. Chen L, Tredget EE, Wu PYG, Wu Y: Paracrine factors of mesenchymal stem cells recruit macrophages and endothelial lineage cells and enhance wound healing. PloS One 2008, 3:e1886.

70. Amé-Thomas P, Maby-El Hajjami H, Monvoisin C, et al: Human mesenchymal stem cells isolated from bone marrow and lymphoid organs support tumor B-cell growth: role of stromal cells in follicular lymphoma pathogenesis. Blood 2007, 109:693-702.

71. Secchiero P, Zorzet S, Tripodo C, Corallini F, et al: Human bone marrow mesenchymal stem cells display anti-cancer activity in SCID mice bearing disseminated non-Hodgkin's lymphoma xenografts. PLOS One 2010, 5(6):e11140.

72. Khakoo AY, Pati S, Anderson SA, et al: Human mesenchymal stem cells exert potent antitumorigenic effects in a model of Kaposi's sarcoma. $J$ Exp Med 2006, 203:1235-1247

73. Otsu K, Das S, Houser SD, et al: Concentration-dependent inhibition of angiogenesis by mesenchymal stem cells. Blood 2009, 113:4197-4205.

74. Thorgeirsson SS, Grisham JW: Hematopoietic cells as hepatocyte stem cells: a critical review of the evidence. Hepatology 2006, 43:2-8.

75. Sancho-Bru P, Najimi M, Caruso M, et al: Stem and progenitor cells for liver repopulation: can we standardize the process from bench to bedside? Gut 2009, 58:594-603

76. Lazennec G, Jorgensen C: Concise Review: Adult multipotent stromal cells and cancer: risk or benefit? Stem Cells 2008, 26:1387-1394.

77. Marini FC: The complex love-hate relationship between mesenchymal stromal cells and tumors. Cytotherapy 2009, 11:375-376.

78. Lu YR, Yuan Y, Wang XJ, et al: The growth inhibitory effect of mesenchymal stem cells on tumor cells in vitro and in vivo. Cancer Biol Ther 2008, 7(2):245-51.

79. Piscaglia AC, Campanale M, Gasbarrini A, Gasbarrini G: Stem Cell-Based Therapies for Liver Diseases:State of theArt andNewPerspectives. Stem Cells International 2010, Article ID 259461, 10 pages.

doi:10.1186/1756-9966-30-49

Cite this article as: Abdel aziz et al:: Efficacy of Mesenchymal Stem Cells in Suppression of Hepatocarcinorigenesis in Rats: Possible Role of Wnt Signaling. Journal of Experimental \& Clinical Cancer Research 2011 30:49.

\section{Submit your next manuscript to BioMed Central and take full advantage of:}

- Convenient online submission

- Thorough peer review

- No space constraints or color figure charges

- Immediate publication on acceptance

- Inclusion in PubMed, CAS, Scopus and Google Scholar

- Research which is freely available for redistribution

Submit your manuscript at www.biomedcentral.com/submit
C Biomed Central 